\title{
Perbedaan Self-regulated Learning Siswa Sekolah Menengah Kejuruan berdasarkan Jenis Kelamin
}

\author{
Wahyu Nanda Eka Saputra, Said Alhadi, Agus Supriyanto, Claudy Desya Wiretna, Babay \\ Baqiyatussolihat \\ Program Studi Bimbingan dan Konseling, Fakultas Keguruan dan Ilmu Pendidikan, \\ Universitas Ahmad Dahlan, Jl. Pramuka No. 42, Yogyakarta, Daerah Istimewa Yogyakarta, Indonesia 55161 \\ E-mail: said.alhadi@bk.uad.ac.id
}

Artikel diterima: 5 Juni 2018; direvisi: 13 November 2018; disetujui: 24 November 2018

\begin{abstract}
The purpose of this study was to identify the differences in self-regulated learning of male and female students in Sekolah Menengah Kejuruan Muhammadiyah in Yogyakarta, Special Region of Yogyakarta, Indonesia. This quantitative study using comparative method involving 414 students consisting of 226 male students and 188 female students as sample. The sample selection used Stratified Random Sampling technique. The instrument was the Self-regulated Learning Scale. To identify the differences in self-regulated learning of male and female students, Independent Sample Test were used. The results showed that there were significant differences between self-regulated learning of male and female students at Sekolah Menengah Kejuruan Muhammadiyah in Yogyakarta. And, self-regulated learning of female student was higher than male students. The particular study recommended the need for counseling services to improve student self-regulated learning.
\end{abstract}

Keywords: comparison; self-regulated learning; vocational high school

\begin{abstract}
Abstrak: Tujuan penelitian ini adalah untuk mengidentifikasi perbedaan self-regulated learning siswa laki-laki dan perempuan di Sekolah Menengah Kejuruan (SMK) Muhammadiyah Kota Yogyakarta, Daerah Istimewa Yogyakarta, Indonesia. Penelitian kuantitatif menggunakan metode komparatif ini melibatkan 414 siswa yang terdiri dari 226 siswa laki-laki dan 188 siswa perempuan sebagai sampel. Pemilihan sampel menggunakan teknik Stratified Random Sampling. Instrumen yang digunakan adalah Skala Self-regulated Learning. Analisis Independent Sample Test digunakan untuk mengidentifikasi perbedaan self-regulated learning siswa laki-laki dan perempuan. Hasil menunjukkan bahwa terdapat perbedaan yang signifikan antara self-regulated learning siswa laki-laki dan siswa perempuan di SMK Muhammadiyah Yogyakarta, dimana self-regulated learning siswa perempuan lebih tinggi. Penelitian ini merekomendasikan perlu adanya layanan konseling untuk meningkatkan self-regulated learning siswa.
\end{abstract}

Kata kunci: komparasi; self-regulated learning; SMK

Prestasi akademik merupakan salah satu indikator utama keberhasilan siswa dalam menjalani proses belajar di sekolah. Oleh sebab itu, berbagai upaya harus dilakukan untuk mendukung tercapainya keberhasilan siswa dalam proses belajar di sekolah (Palmer, Davis, \& Maramba, 2010; Palmer, Davis, \& Thompson, 2010). Secara khusus, salah satu unsur yang dapat mendukung keberhasilan siswa dalam menjalani proses pembelajaran di sekolah adalah motivasi intrinsik untuk belajar (Alhadi \& Saputra, 2017; Fan \& Williams, 2010; Froiland dkk., 2012; Logan, Medford, \& Hughes, 2011; Niehaus, Rudasill, \& Adelson, 2012; Walker, Greene, \& Mansell, 2006). Motivasi intrinsik 
yang rendah, akan memicu rendahnya keberhasilan siswa dalam menjalani proses belajar di sekolah. Sebaliknya, motivasi intrinsik yang tinggi, akan memicu siswa untuk mencapai keberhasilan dalam proses pembelajaran di sekolah.

Berbagai masalah muncul di sekolah terkait dengan permasalahan belajar. Salah satu masalah yang sering muncul adalah penundaan mengerjakan tugas atau sering disebut dengan prokrastinasi akademik. Sebuah penelitian menyebutkan bahwa terdapat sebesar 17,2\% pelajar Sekolah Menengah Pertama (SMP) di kota Yogyakarta yang mengalami prokrastinasi tinggi, 77,1\% mengalami prokrastinasi sedang, dan 5,7\% mengalami prokrastinasi rendah (Munawaroh, Alhadi, \& Saputra, 2017). Siswa yang sering melakukan penundaan mengerjakan tugas akan cenderung memiliki tingkat kemandirian belajar atau yang sering disebut self-regulated learning rendah (Corkin, Shirley, \& Lindt, 2011; Rakes \& Dunn, 2010; Wäschle dkk., 2014).

Kesadaran akan pentingnya keterampilan self-regulated learning perlu dimiliki oleh setiap siswa, termasuk siswa SMK. Kesadaran siswa akan pentingnya self-regulated learning akan memacu siswa mengatur dirinya menampilkan kegiatan belajar yang maksimal dan akan menghindarkan siswa dari penurunan pencapaian prestasi belajar (Azevedo dkk., 2010; Efklides, 2011; Zimmerman, 2013). Assessment tentang keterampilan self-regulated learning siswa SMK dapat membantu mereka menyadari tingkat self-regulated learning yang mereka miliki (Clark, 2012; Lindner \& Harris, 1993) dan hal tersebut dapat membantu mereka mengembangan keterampilan self-regulated learning.

Permasalahan tentang self-regulated learning masih menjadi pekerjaan rumah bagi berbagai pihak, termasuk guru bimbingan dan konseling atau konselor sekolah. Upaya positif sering diabaikan oleh mahasiswa, sehingga proses belajar yang dilakukan oleh mahasiswa tidak maksimal. Jika permasalahan ini tidak segera diselesaikan, siswa akan mengalami dampak negatif. Sering pula siswa tidak menyadari bahwa mereka kurang memiliki keterampilan self-regulated learning. Hal ini menjadikan konselor sekolah memerlukan upaya yang lebih untuk merancang strategi membangun dan mengembangkan self-regulated learning siswa.

Jenis kelamin dapat menjadi salah satu komponen yang turut menjadi penentu tingkat selfregulated learning (Virtanen \& Nevgi, 2010; Zimmerman \& Martinez-Pons, 1990). Siswa laki-laki dan perempuan kemungkinan memiliki kecenderungan kemampuan self-regulated learning yang berbeda. Secara lebih spesifik penelitian ini akan mengidentifikasi perbedaan self-regulated learning siswa laki-laki dan perempuan pada tingkat SMK. Self-regulated learning siswa diukur dengan menggunakan Skala Self-regulated Learning yang terdiri dari 43 butir pernyataan dan memiliki reliabilitas tinggi (Alhadi, Saputra, \& Supriyanto, 2018). Lokasi penelitian di sekolah tingkat SMK menjadi salah satu pembeda dengan penelitian-penelitian sebelumnya. Dipilihnya latar SMK sebagai lokasi penelitian karena perbedaan budaya sekolah antara SMK dengan Sekolah Menengah Atas (SMA), yang mana orientasi siswa SMK setelah lulus adalah bekerja. Kondisi ini menuntut siswa untuk memiliki kemampuan pengaturan diri dalam belajar yang mengarah pada pencapaian prestasi belajar yang maksimal, sehingga akan menunjang kesuksesan dan kematangan karier mereka ketika terjun ke dunia kerja (Aji, 2010; Juwitaningrum, 2013; Lestari \& Siswanto, 2015). Lebih jauh lagi, siswa SMK perlu berpikir lebih rasional untuk memiliki kejelasan arah karier (Jarkawi, Ridhani, \& Susanto, 2017).

Hipotesis penelitian ini adalah terdapat perbedaan tingkat self-regulated learning yang signifikan antara siswa laki-laki dan perempuan pada SMK Muhammadiyah di Kota Yogyakarta. Hipotesis tersebut diuji melalui proses penelitian komparatif untuk mengidentifikasi perbedaannya. Hasil penelitian ini dapat menjadi dasar pertimbangan para praktisi pendidikan di lapangan dalam upaya mengembangkan self-regulated learning siswa dengan mempertimbangkan jenis kelamin siswa. Ketepatan dan keakuratan praktisi dalam menyusun program kerja bimbingan dan konseling memberikan efek nyata terhadap perubahan tingkat self-regulated learning yang dimiliki oleh siswa SMK. 


\section{METODE}

Rancangan penelitian ini adalah komparatif. Penelitian komparatif memiliki sifat membandingkan persamaan dan perbedaan dua atau lebih sifat-sifat dan fakta-fakta objek yang diteliti berdasarkan suatu kerangka pemikiran yang telah dibuat. Penelitian komparatif digunakan untuk membandingkan antara dua kelompok atau lebih dalam suatu variabel tertentu, yang dalam hal ini adalah self-regulated learning siswa SMK berjenis kelamin laki-laki dan perempuan. Penelitian komparatif digambarkan pada gambar 1.

Penelitian ini dirancang sebagai penelitian komparatif, dengan sampel 414 siswa SMK Muhammadiyah di Kota Yogyakarta, Daerah Istimewa Yogyakarta, Indonesia. Sampel terdiri dari 226 siswa SMK berjenis kelamin laki-laki dan 188 siswa SMK berjenis kelamin perempuan. Teknik pengambilan sampel pada penelitian ini adalah stratified random sampling. Instrumen yang digunakan adalah Skala Self-regulated Learning yang terdiri dari 43 butir pernyataan yang telah diuji validitasnya dan telah dinyatakan valid. Selain itu, hasil uji reliabilitasnya menunjukkan koefisien 0,880 dan dinyatakan dalam kategori reliabilitas tinggi. Analisis data untuk mengidentifikasi perbedaan self-regulated learning siswa laki-laki dan perempuan menggunakan rumus Independent Samples Test dengan bantuan program SPSS for Windows Release 20.

Tahap-tahap yang dilakukan dalam penelitian ini dijabarkan dalam lima tahapan. Pertama yang dilakukan adalah menentukan masalah yang diteliti. Masalah yang diteliti dalam penelitian ini adalah variabel self-regulated learning. Kedua, menentukan kelompok yang memiliki karakteristik yang diteliti. Kelompok yang diteliti dalam penelitian ini adalah siswa SMK Muhammadiyah di Kota Yogyakarta berjenis kelamin laki-laki yang jumlah sampelnya terdiri dari 226. Ketiga, menentukan kelompok pembanding. Kelompok pembanding dalam penelitian ini adalah siswa SMK Muhammadiyah di Kota Yogyakarta berjenis kelamin perempuan yang jumlah sampelnya adalah 188 siswa. Keempat, melakukan pengumpulan data. Data dikumpulkan dengan menggunakan Skala Self-regulated Learning. Kelima, melakukan analisis data. Data yang telah terkumpul dianalisis menggunakan rumus Independent Samples Test.

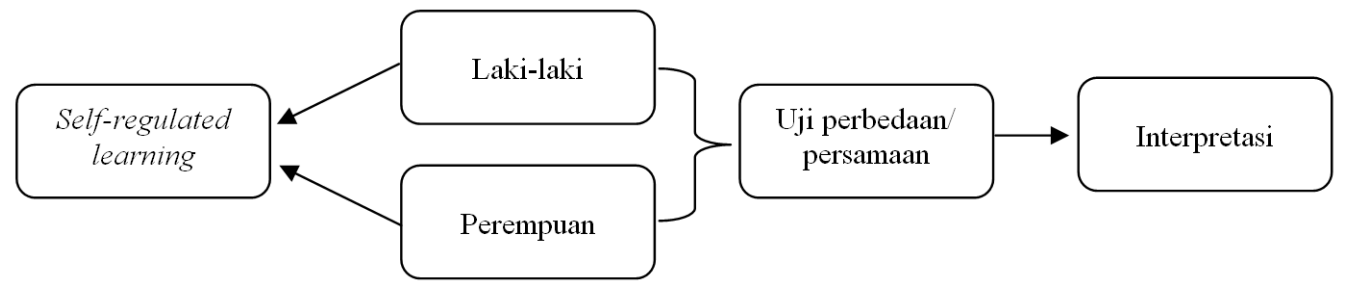

\section{Gambar 1 Rancangan Penelitian Komparatif}

\section{HASIL}

Pengolahan data Independent Samples Test menggunakan bantuan software SPSS versi 20. Analisis ini dipilih untuk melihat ada atau tidaknya perbedaan self-regulated learning siswa ditinjau dari jenis kelamin. Hasil uji beda self-regulated learning ditinjau dari jenis kelamin disajikan pada tabel 1.

Pada tabel 1 dan 2, F yang diperoleh ialah 8,517 dengan signifikansi 0,504 yang berarti lebih besar dari $0,05(0,504>0,05)$ hal ini berarti varian kelompok populasi adalah homogen. Dengan demikian persyaratan homogenitas untuk analisis komparasi terpenuhi. Selanjutnya, dari hasil analisis data diperoleh koefisien $\mathrm{t}$ hitung sebesar $-5,828$ dengan probabilitas 0,000 apabila dibandingkan dengan 0,05 maka nilai probabilitasnya lebih kecil dari 0,05 yang artinya terdapat perbedaan self-regulated learning siswa ditinjau dari jenis kelamin. Dengan demikian dapat diketahui bahwa terdapat perbedaan self-regulated learning yang signifikan antara siswa laki-laki dan perempuan.

Hasil analisis data menunjukkan bahwa tingkat self-regulated learning siswa perempuan lebih tinggi daripada siswa laki-laki. Hal tersebut ditunjukkan dengan nilai mean tingkat self-regulated learning siswa perempuan sebesar 129,1596 sedangkan tingkat self-regulated learning siswa laki- 
Tabel 1 Output Group Statistics menggunakan SPSS

\begin{tabular}{llcccc}
\hline & Jenis Kelamin & N & Mean & Std. Deviation & Std. Error Mean \\
\cline { 2 - 6 } Tingkat Self- & Laki-laki & 226 & 120,3717 & 16,79190 & 1,11698 \\
regulated Learning & Perempuan & 188 & 129,1596 & 13,22193 & 0,96431 \\
\hline
\end{tabular}

Tabel 2 Output Independent Samples Test menggunakan SPSS

\begin{tabular}{|c|c|c|c|c|c|c|c|c|c|c|}
\hline \multirow{5}{*}{$\begin{array}{l}\text { Tingkat } \\
\text { Self- } \\
\text { regu } \\
\text { lated } \\
\text { Learn } \\
\text { ing }\end{array}$} & \multirow[b]{4}{*}{$\begin{array}{l}\text { Equal } \\
\text { variances } \\
\text { assumed }\end{array}$} & \multicolumn{3}{|c|}{$\begin{array}{l}\text { Levene's Test } \\
\text { for Equality } \\
\text { of Variances }\end{array}$} & \multicolumn{6}{|c|}{ t-test for Equality of Means } \\
\hline & & \multirow[t]{2}{*}{$F$} & \multirow[t]{2}{*}{ Sig. } & \multirow[t]{2}{*}{$T$} & \multirow[t]{2}{*}{$D f$} & \multirow[t]{2}{*}{$\underset{\text { Sig. }}{\text { (2-tailed) }}$} & \multirow{2}{*}{$\begin{array}{l}\text { Mean } \\
\text { Differ } \\
\text { ence }\end{array}$} & \multirow{2}{*}{$\begin{array}{l}\text { Std. } \\
\text { Error } \\
\text { Differ } \\
\text { ence }\end{array}$} & \multicolumn{2}{|c|}{$\begin{array}{c}\text { 95\% Confidence } \\
\text { Interval of the } \\
\text { Difference }\end{array}$} \\
\hline & & & & & & & & & Lower & Upper \\
\hline & & 0,517 & 0,504 & $-5,828$ & 412 & 0,000 & $-8,78789$ & 1,50785 & $-11,75192$ & $-5,82386$ \\
\hline & $\begin{array}{l}\text { Equal } \\
\text { variances } \\
\text { not } \\
\text { assumed }\end{array}$ & & & $-5,955$ & 410,806 & 0,000 & $-8,78789$ & 1,47565 & $-11,68866$ & $-5,88713$ \\
\hline
\end{tabular}

laki sebesar 120,3717. Mean tingkat self-regulated learning siswa perempuan lebih besar daripada tingkat self-regulated learning siswa laki-laki. Pada bagian selanjutnya akan dibahas secara komprehensif hasil dari penelitian ini, melibatkan diskusi dengan hasil penelitian terdahulu dan konfirmasi teori.

\section{PEMBAHASAN}

Berdasarkan hasil penelitian, terdapat perbedaan self-regulated learning antara siswa lakilaki dan perempuan di SMK Muhammadiyah di Kota Yogyakarta, Daerah Istimewa Yogyakarta, Indonesia. Jika ditilik dari nilai rata-rata, tingkat self-regulated learning siswa perempuan SMK Muhammadiyah di Kota lebih tinggi dibandingkan dengan tingkat self-regulated learning siswa laki-laki. Siswa yang memiliki tingkat self-regulated learning tinggi, memiliki peluang yang lebih besar untuk mencapai prestasi akademik yang diinginkan daripada siswa yang memiliki tingkat selfregulated learning yang rendah (Broadbent \& Poon, 2015; Kitsantas, Steen, \& Huie, 2017). Hal ini disebabkan karena mereka memiliki kemampuan untuk mengatur dirinya untuk tetap belajar secara mandiri walaupun tidak dikondisikan oleh guru. Kebiasaan ini yang akan dapat memicu siswa untuk selalu siap dengan berbagai pembelajaran yang diberikan oleh guru di sekolah. Siswa perempuan cenderung melaporkan penggunaan latihan, organisasi, metakognisi, keterampilan manajemen waktu, elaborasi, dan usaha yang lebih baik daripada siswa laki-laki (Bidjerano, 2005). Kemampuan mengorganisasikan diri sendiri dengan kondisi yang ada dilingkungannya menjadi alat kuat bagi siswa untuk mengalami proses pembelajaran yang maksimal.

Penelitian terdahulu juga menyebutkan bahwa terdapat perbedaan yang signifikan pada tingkat self-regulated learning siswa laki-laki dan perempuan (Bembenutty, 2007). Bahkan terdapat temuan penelitian yang menyimpulkan bahwa siswa laki-laki memiliki kecenderungan untuk fokus pada tujuan kinerja pembelajaran serta menggunakan strategi pembelajaran yang lebih mudah seperti hafalan jika dibandingkan dengan siswa perempuan (Niemivirta, 1997). Salah satu indikator nyata yang dapat menjadi bukti bahwa siswa perempuan memiliki tingkat self-regulated learning yang lebih tinggi daripada siswa laki-laki adalah lebih tingginya prestasi akademik siswa perempuan daripada 
laki-laki ketika berada di sekolah. Salah satu penelitian juga mendukung pernyataan tersebut yang menyimpulkan bahwa pencapaian prestasi akademik siswa perempuan ketika di sekolah memiliki kecenderungan lebih baik daripada siswa laki-laki (Ray, Garavalia, \& Gredler, 2003).

Self-regulated learning yang dimiliki oleh siswa dipengaruhi oleh situasi yang ada pada lingkungan siswa dan juga tidak terlepas dari dukungan sosial yang diberikan kepada mereka (Rachmah, 2015). Lingkungan yang tercipta pada siswa perempuan memberikan kesempatan pada mereka untuk saling memberikan penguatan dan perhatian terhadap berkembangnya tingkat selfregulated learning, sehingga kondisi lingkungan tersebut semakin menguatkan untuk meningkatkan self-regulated learning.

Siswa laki-laki memiliki keterikatan kuat dengan teman sebayanya, namun keterikatan tersebut justru memberikan dampak buruk, yang salah satu dampaknya adalah menurunnya kualitas selfregulated learning yang mereka miliki. Ilustrasi tersebut seperti halnya penelitian lain yang menunjukkan bahwa self-regulated learning siswa dan konformitas teman sebaya berpengaruh pada prokrastinasi akademik (Safa'ati, 2017). Tinggi atau rendahnya prokrastinasi akademik itu sendiri menjadi salah satu prediktor baik atau buruknya keterampilan self-regulated learning yang dimiliki oleh siswa (Balkis \& Duru, 2016; Hong et al., 2015). Semakin tinggi prokrastinasi akademik, maka semakin rendah tingkat self-regulated learning. Sebaliknya, semakin rendah prokrastinasi akademik, maka semakin tinggi tingkat self-regulated learning siswa.

Beberapa penelitian lain justru menunjukkan hasil yang berkebalikan dengan temuan penelitian ini. Salah satu penelitian menyimpulkan bahwa tidak ada perbedaan yang signifikan antara siswa lakilaki dan perempuan terhadap tingkat self-regulated learning dan motivasi siswa untuk berprestasi (Yukselturk \& Bulut, 2009). Perbedaan kedua hasil penelitian ini dapat menjadi landasan penelitian selanjutnya untuk mengidentifikasi alasan terdapatnya perbedaan hasil penelitian ini, yang tentunya menarik untuk dikaji. Tinggi atau rendahnya tingkat self-regulated learning dapat menjadi alasan konselor sekolah dan pemangku kepentingan terkait untuk menyusun sebuah program kegiatan dalam rangka meningkatkan self-regulated learning siswa.

Self-regulated learning sendiri menjadi variabel penting bagi siswa untuk mencapai kesuksesan akademik yang mereka jalani di sekolah. Hal tersebut menjadi alasan mendasar bagi siswa untuk memahami dan menyadari tingkat self-regulated learning mereka serta mampu membuat perubahan apabila self-regulated learning mereka rendah. Hal ini dikarenakan self-regulated learning memiliki pengaruh signifikan terhadap performa akademik (Wilson \& Narayan, 2016) juga prestasi akademik (Broadbent \& Poon, 2015; Dent \& Koenka, 2016; Wolters \& Hussain, 2015), yang berarti selain performa akademik yang baik, tingkat self-regulated learning siswa yang tinggi akan mendorong siswa mencapai prestasi akademik yang maksimal sesuai dengan harapan setiap siswa.

Peran konselor sekolah begitu vital untuk membantu siswa mengidentifikasi tingkat selfregulated learning. Tingkat self-regulated learning ini menjadi dasar konselor sekolah dalam menyusun program bimbingan dan konseling guna membuat perubahan, yaitu meningkatnya selfregulated learning siswa. Hal ini dilakukan konselor agar materi yang diberikan oleh konselor sekolah sesuai dengan kebutuhan yang ada pada diri siswa, sehingga program bimbingan dan konseling yang dikembangkan tepat sasaran serta sesuai dengan situasi dan kondisi siswa di sekolah.

\section{SIMPULAN}

Self-regulated learning merupakan salah satu variabel penting bagi kesuksesan siswa dalam bidang akademik. Kesadaran siswa akan tingkat self-regulated learning perlu dimiliki agar dapat menunjang keberhasilannya dalam bidang akademik. Penelitian ini menyimpulkan bahwa siswa SMK perempuan memiliki keterampilan self-regulated learning yang lebih baik daripada siswa SMK laki-laki. Hasil penelitian ini seyogyanya dapat menjadi dasar konselor sekolah dalam menyusun program bimbingan dan konseling untuk meningkatkan self-regulated learning dengan memperhatikan karakteristik siswa SMK laki-laki dan perempuan. Selain itu, hasil penelitian ini dapat menjadi dasar penelitian selanjutnya untuk dapat meningkatkan; menciptakan; atau menguji model intervensi tertentu untuk meningkatkan self-regulated learning siswa SMK. 


\section{DAFTAR RUJUKAN}

Aji, R. (2010). Hubungan antara Locus of Control Internal dengan Kematangan Karir pada Siswa Kelas XII SMK N 4 Purworejo. (Doctoral dissertation) Universitas Diponegoro.

Alhadi, S., \& Saputra, W. N. E. (2017). The Relationship between Learning Motivation and Learning Outcome of Junior High School Students in Yogyakarta.

Alhadi, S., Saputra, W., \& Supriyanto, A. (2018). The Analysis of Validity and Reliability of Selfregulated Learning Scale. In Proceedings of the 1st International Conference on Education Innovation (ICEI 2017). Paris, France: Atlantis Press. https://doi.org/10.2991/icei-17.2018.74

Azevedo, R., Johnson, A., Chauncey, A., \& Burkett, C. (2010). Self-regulated Learning with MetaTutor: Advancing the Science of Learning with MetaCognitive Tools. In New Science of Learning (pp. 225-247). Springer.

Balkis, M., \& Duru, E. (2016). Procrastination, Self-regulation Failure, Academic Life Satisfaction, and Affective Well-being: Underregulation or Misregulation Form. European Journal of Psychology of Education, 31(3), 439-459. https://doi.org/10.1007/s10212-015-0266-5

Bembenutty, H. (2007). Self-regulation of Learning and Academic Delay of Gratification: Gender and Ethnic Differences among College Students. Journal of Advanced Academics, 18(4), 586616.

Bidjerano, T. (2005). Gender Differences in Self-Regulated Learning.

Broadbent, J., \& Poon, W. L. (2015). Self-regulated Learning Strategies \& Academic Achievement in Online Higher Education Learning Environments: A Systematic Review. The Internet and Higher Education, 27, 1-13.

Clark, I. (2012). Formative Assessment: Assessment is For Self-regulated Learning. Educational Psychology Review, 24(2), 205-249.

Corkin, D. M., Shirley, L. Y., \& Lindt, S. F. (2011). Comparing Active Delay and Procrastination From A Self-regulated Learning Perspective. Learning and Individual Differences, 21(5), 602606.

Dent, A. L., \& Koenka, A. C. (2016). The Relation Between Self-regulated Learning and Academic Achievement Across Childhood and Adolescence: A Meta-analysis. Educational Psychology Review, 28(3), 425-474.

Efklides, A. (2011). Interactions of Metacognition with Motivation and Affect in Self-regulated Learning: The MASRL Model. Educational Psychologist, 46(1), 6-25.

Fan, W., \& Williams, C. M. (2010). The Effects of Parental Involvement on Students' Academic Self-efficacy, Engagement and Intrinsic Motivation. Educational Psychology, 30(1), 53-74.

Froiland, J. M., Oros, E., Smith, L., \& Hirchert, T. (2012). Intrinsic Motivation to Learn: The Nexus between Psychological Health and Academic Success. Contemporary School Psychology: Formerly" The California School Psychologist", 16(1), 91-100.

Hong, J.-C., Hwang, M.-Y., Kuo, Y.-C., \& Hsu, W.-Y. (2015). Parental Monitoring and Helicopter Parenting Relevant to Vocational Student's Procrastination and Self-regulated Learning. Learning and Individual Differences, 42, 139-146. https://doi.org/10.1016/j.lindif.2015.08.003

Jarkawi, J., Ridhani, A. R., \& Susanto, D. (2017). Strategi Bimbingan dan Konseling Karier Bermutu pada Sekolah Menengah Kejuruan Syuhada Banjarmasin. Jurnal Kajian Bimbingan dan Konseling, 2(3), 123-130. https://doi.org/dx.doi.org/10.17977/um001v2i32017p123

Juwitaningrum, I. (2013). Program Bimbingan Karir untuk Meningkatkan Kematangan Karir Siswa SMK. PSIKOPEDAGOGIA Jurnal Bimbingan dan Konseling, 2(2), 132-147. https://doi. org/10.12928/psikopedagogia.v2i2.2580 
Kitsantas, A., Steen, S., \& Huie, F. (2017). The Role of Self-regulated Strategies and Goal Orientation in Predicting Achievement of Elementary School Children. International Electronic Journal of Elementary Education, 2(1), 65-81.

Lestari, I., \& Siswanto, B. T. (2015). Pengaruh Pengalaman Prakerin, Hasil Belajar Produktif dan Dukungan Sosial Terhadap Kesiapan Kerja Siswa SMK. Jurnal Pendidikan Vokasi, 5(2), 183194.

Lindner, R. W., \& Harris, B. (1993). Self-Regulated Learning: Its Assessment and Instructional Implications. Educational Research Quarterly, 16(2), 29-37.

Logan, S., Medford, E., \& Hughes, N. (2011). The Importance of Intrinsic Motivation for High and Low Ability Readers' Reading Comprehension Performance. Learning and Individual Differences, 21(1), 124-128.

Munawaroh, M. L., Alhadi, S., \& Saputra, W. N. E. (2017). Tingkat Prokrastinasi Akademik Siswa Sekolah Menengah Pertama di Kota Yogyakarta. Jurnal Kajian Bimbingan Dan Konseling, 2(1), 26-31.

Niehaus, K., Rudasill, K. M., \& Adelson, J. L. (2012). Self-efficacy, Intrinsic Motivation, and Academic Outcomes among Latino Middle School Students Participating in An After-school Program. Hispanic Journal of Behavioral Sciences, 34(1), 118-136.

Niemivirta, M. (1997). Gender Differences in Motivational-Cognitive Patterns of Self-Regulated Learning.

Palmer, R. T., Davis, R. J., \& Maramba, D. C. (2010). Role of An HBCU in Supporting Academic Success for Underprepared Black Males. Negro Educational Review, 61(1-4), 85.

Palmer, R. T., Davis, R. J., \& Thompson, T. (2010). Theory Meets Practice: HBCU Initiatives that Promote Academic Success among African Americans in STEM. Journal of College Student Development, 51(4), 440-443.

Rachmah, D. N. (2015). Regulasi Diri dalam Belajar pada Mahasiswa yang Memiliki Peran Banyak. Jurnal Psikologi, 42(1), 61-77. https://doi.org/10.22146/jpsi.6943

Rakes, G. C., \& Dunn, K. E. (2010). The Impact of Online Graduate Students' Motivation and SelfRegulation on Academic Procrastination. Journal of Interactive Online Learning, 9(1), 78-93

Ray, M. W., Garavalia, L. S., \& Gredler, M. E. (2003). Gender Differences in Self-Regulated Learning, Task Value, and Achievement in Developmental College Students.

Safa'ati, E. (2017). Peran Regulasi Diri dan Konformitas Teman Sebaya dengan Prokrastinasi Akademik Mahasiswa Universitas Muria Kudus. Prosiding Konferensi Nasional Peneliti Muda Psikologi Indonesia, 2(1), 75-84.

Virtanen, P., \& Nevgi, A. (2010). Disciplinary and Gender Differences among Higher Education Students in Self-regulated Learning Strategies. Educational Psychology, 30(3), 323-347.

Walker, C. O., Greene, B. A., \& Mansell, R. A. (2006). Identification with Academics, Intrinsic/ extrinsic Motivation, and Self-efficacy as Predictors of Cognitive Engagement. Learning and Individual Differences, 16(1), 1-12.

Wäschle, K., Allgaier, A., Lachner, A., Fink, S., \& Nückles, M. (2014). Procrastination and Selfefficacy: Tracing Vicious and Virtuous Circles in Self-regulated Learning. Learning and Instruction, 29, 103-114.

Wilson, K., \& Narayan, A. (2016). Relationships among Individual Task Self-efficacy, Self-regulated Learning Strategy Use and Academic Performance in A Computer-supported Collaborative Learning Environment. Educational Psychology, 36(2), 236-253.

Wolters, C. A., \& Hussain, M. (2015). Investigating Grit and Its Relations with College Students' Self-Regulated Learning and Academic Achievement. Metacognition and Learning, 10(3), 293-311. 
Yukselturk, E., \& Bulut, S. (2009). Gender Differences in Self-regulated Online Learning Environment. Journal of Educational Technology \& Society, 12(3), 12-22.

Zimmerman, B. J. (2013). Theories of Self-regulated Learning and Academic Achievement: An Overview and Analysis. In Self-regulated Learning and Academic Achievement (pp. 10-45). Routledge.

Zimmerman, B. J., \& Martinez-Pons, M. (1990). Student Differences in Self-regulated Learning: Relating Grade, Sex, and Giftedness to Self-efficacy and Strategy Use. Journal of Educational Psychology, 82(1), 51-59. 